\title{
A Hand Book of Medicinal Plants of Nepal
}

\author{
Authors \\ Publisher \\ Price \\ Pages \\ : T. Watanabe, K.K. Rajbhandari, K.J. Malla and S. Yahara \\ Year of Publication : 2005 \\ ISBN \\ 974-7799-58-8
}

Some of the oldest known medicinal systems of the world such as Ayurveda of the Indus civilization, Arabian medicine of Mesopotamia, Chinese and Tibetan medicine of the Yellow River civilization of China and Kempo of the Japanese are all based mostly on plants. Interestingly, Allopathy-today's most familiar medical system which is primarily based on synthetic chemicals for medication, has these days, shown greater interest in using chemicals derived from plants. This explains how important is, and will remain the medicinal use of plants for the mankind.

The central Himalaya is a huge repository of such medicinal plants. Nepal for being located at this portion of the Himalaya, has always remained a

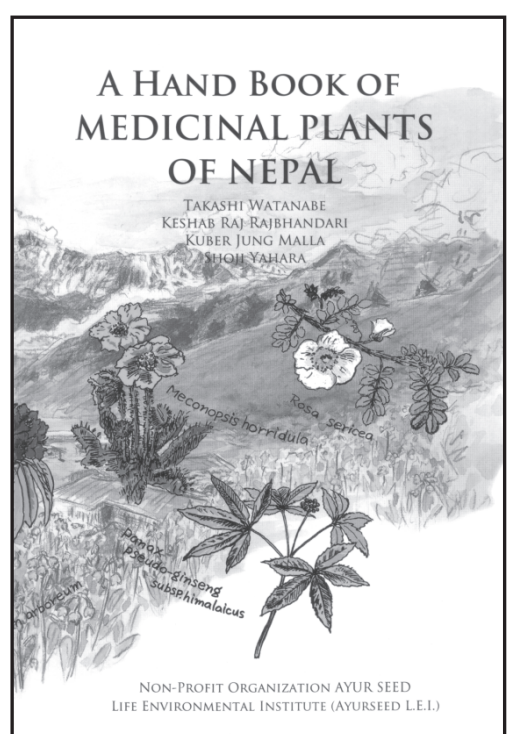
place of great interest to the botanists and phytochemists involved in researching medicinal herbs. It would be a matter of great surprise for the readers to know that the first botanical exploration was done in Nepal in 1802/3 AD by a medicinal practitioner Mr. Buchanan Hamilton. This was followed by Mr. N. Wallich in $1820 / 2$ 1. Both of these had brief ethnobotanical notes, which were recorded by D. Don and Wallich himself. Since then workers from all around the world are actively involved in researching medicinal uses of plants from the Nepal Himalaya. Many drugs have been formulated, marketed, and patented. The Japanese are among those who have not only contributed to the medico-botany of Nepal, but also other areas of botanical science. Of the expected 7000 species of flowering plant in Nepal, 10 percent are reported to be medicinal. Proper documentation of this resource would mean a great contribution to Nepal's meteria medica. The present Hand Book is one such contribution.

Amongst the four authors of this Handbook, Dr. Takashi Watanabe--the first author, had served the then Department of Medicinal Plants (now Department of Plant Resources) as a Japanese volunteer during the '80s. After completion of his Ph.D in Pharmacy from Kitasato University, Tokyo, he continued to work in medicinal plants of Nepal. With the help of two sincere and renowned botanists of the Department, namely Dr. K.K. Rajbhandary and Mr. K.J. Malla, along with an experienced phyto-chemist-Dr. S. Yahara (Associate Professor of Kumamoto University), Dr. Watanabe might have found medicinal plants a better topic for writing a book. This is undoubtedly a welcoming step.

The book contains systematic account of 108 naturally occurring medicinal plants of Nepal. The text of each plant is divided into two major portions: the first devoted to distribution, illustration, botanical description, useful parts and medicinal uses of plants. And the second but more important is the inclusion of chemical constituents of the plants used in medicine. The work is thus of a too comprehensive character for one author to complete. Hence, it is none other than a result of a successful team effort of pertinent disciplines.

I have no idea who amongst the team, has originally designed the book, but I am glad to see a team of professionals--two Nepali botanists and the same number of Japanese pharmacists have produced such a tremendous work. The work, which seems to be originally designed to serve more specifically for the botanists and phyto-chernists, will help uplift our understanding on Nepali medicinal plants thereby serving the mankind. No wonder that serious readers and libraries will find it as a valuable reference material.

Dr. Sushim Ranjan Baral

Dept. of Forest Research \& Survey 